\title{
Beyond "Teach a Man to Fish": Communal Meta-cognition as the Key to Sustainable Professional Development
}

\author{
Ken Foster ${ }^{a}$ \\ ${ }^{a}$ MD, Assistant Professor of Surgery, Northern Ontario School of Medicine, Canada
}

\begin{abstract}
Improvement in the quality of aid and development in a community requires a feedback loop within the community, known as "communal meta-cognition." This is relevant to medical education in resource-poor countries and is illustrated with the author's own surgical experience. The usual source of truth is unquestioned allegiance to established wisdom rather than the dynamic state that comes through the feedback loop of asking questions, most importantly of one's self. Some elements of what this might look like in a medical education context are illustrated.
\end{abstract}

\section{Introduction}

In 2010, the Lancet charted a path into the 21 st century with its commissioned report "Medical Education for the 21st Century" put together by recognized leaders in the field. ${ }^{1}$ As a manifesto outlining where medicine should go, it represents the top of the game. So why, for me, should it be such a frustrating read? The Lancet report's executive summary states, "Professional education has not kept pace with these challenges, largely because of fragmented, outdated, and static curricula that produce ill-equipped graduates." If the leadership of the medical profession continues to focus on fixing curricula and equipping graduates, then I am afraid that for another generation, especially in the countries where the need is greatest, professional education will continue to lag behind. Knowledge content, including skills in that category, like natural resources in the economic sphere, can often end up doing more harm than good because of the tendency to promote inequity, corruption, and the use of force. To the extent that medical education can be shifted away from maximizing the capacities of individual doctors and towards the promotion of a culture of learning as a community, then change begins to come from within.

One can easily argue that developing curricula and providing resources to increase the capacities of individual practitioners is a good way to exacerbate the human resources gap by facilitating the brain drain. It is hard to argue with the numbers. I know of one African country in which none of the more than 30 United Kingdom certified orthopaedic specialists trained there over a three decades span stayed in the country. Even when the more skilled doctors do stay in their own country, there is a tendency to focus care on those better able to pay for it. Indeed, the medical profession can exploit the poor who are without hope of recompense or prospect of litigation. Although punitive approaches may not lead to decreases in medical error, a culture of accountability can only help when it comes to embedding Hippocratic values and motivation. What I am proposing is a shift of the focus of intervention in medical education from the cognition of the individual practitioner to meta-cognition of the professional community. It is not enough to "teach a man to fish," let alone "give a man a fish." We 
must, in this metaphor, help the community to develop a sustainable fishery.

\section{Meta-cognition}

The term meta-cognition can be described as the awareness or understanding of one's own thinking processes. If this seems too abstract, it might help to outline one way in which this principle could work in practice. The frustration I felt after reading the Lancet article arises in large part because I have spent most of my career in war-torn countries: Afghanistan, Angola, and Yemen. Cultural difference has played a large part in my own experience and Hofstede's analysis in this area has resonated the most strongly. Of the cultural dimensions that he examines, "powerdistance" relates most directly to the source of authority in medical education. ${ }^{2}$ Oddly, this point seems rather noticeably absent from the Lancet report. Although where I currently practice in Canada, application of these same principles (meta-cognition) could stand to be improved, the benefits to be gained would be relatively less. The activity I am proposing, wherever and no matter how imperfectly implemented, must inevitably effect some measure of salutary culture change.

\section{Scenario - Afghan healthcare}

Since the Taliban were ousted in 2001, Afghanistan's healthcare system has seen dramatic change. Western countries invested substantially and analyzed extensively. Healthcare is supposed to be publicly funded and free, although the reality seems otherwise. ${ }^{3}$ The Basic Package of Health Services (BPHS) program focused almost exclusively on low hanging fruit. Subsequently, this has shifted somewhat as a result of ongoing analysis towards a more pragmatic balance that incorporates some essential surgical services. With virtually all of the funding to run the system having come from outside sources such as USAID and EU monies, it has been galling to see several of the best functioning hospitals close because of an approach to funding that blocked local community input. At the same time, one of the biggest hospitals in the capital received massive injections of funding while notoriously failing to correct egregious breaches of clinical and ethical standards. ${ }^{4}$ As an example, the same pair of latex gloves would often be used for several obstetrical deliveries. Cleaning staff of decade's long employment whose dedication was illustrated by their willingness to work often without pay through the worst of the war years were fired and replaced by relatives of the new directorate when the salary scale saw dramatic rises (Personal communication). If they had shown some interest or commitment to working, then justification might be claimed. Although the reader might question why I chose such an extreme example of the damaging impact of aid money, it highlights the lack of feedback both from within the hospital structure and from the local community.

While not denying that large gains were made through the BPHS, my purpose is to ask whether a small percentage of the aid money could be spent to leverage greater accountability. In North America, we are increasingly being encouraged to pursue practice based reflective learning to maintain competency. High-power distance cultures that also place great importance on honor/shame show resistance to exposure of weakness or ignorance, and there is more discomfort with ambiguity or change. ${ }^{3}$ From my years in Afghanistan, Yemen, and Angola, I am convinced that this cultural issue is crucial to medical education. Could not a small part of the investment in health care be spent to promote culture change among health care professionals?

The capacity-building approach of focusing on competencies and resources generally works system wide from the top down, e.g., the BPHS in Afghanistan. William Easterly argues in his book, The White Man's Burden, for more of a "local problem, local solution" approach in which the stakeholders function more directly as local stakeholders. ${ }^{5}$ The proposal that follows is a hybrid of the two, with generic process but local content. Its capacity building focuses on the local professional community rather than the individual practitioner. The goal is not so much to train better doctors, per se, as it is to develop clinical departments that function as learning communities. 
The cities of Qandahar and Herat each have an example of a hospital dramatically improved through the involvement of a local businessman. While such altruistic involvement from the community is highly desirable and fits Easterly's approach, it does not constitute low hanging fruit. Instead, the crucial question in relation to feasibility and fruitfulness lies in the contribution that doctors make to health care. In Afghanistan, they are the dominant players, whether or not the main influencers of health care delivery. What follows is a proposal that would take a tiny proportion of the money spent on health care and use it to promote meta-cognition at the level of hospital clinical departments.

\section{A Proposal}

Clinical departments at all public hospitals in Afghanistan should hold a half-hour, weekly discussion focused on a recent case. Each department would be required to choose a case for discussion on the basis of at least one of these three features: (1) uncertainty, (2) controversy, or (3) bad outcome. The whole department should be involved, and the discussion should engage with the following three questions; (1) What was the case narrative? (2) Were there things that we could have done differently? (3) How do others, elsewhere, manage this kind of problem?

PowerPoint, for all its faults as a medium of expression, can nevertheless help to essentialize and record the key elements and provide a means for coaching feedback and program assessment. In contexts where such discussions pose challenges to traditions and hierarchies, subtle interventions can be helpfully subversive. Provide computer hardware and training in the use of internet access to literature through HINARI as incentive. Make hospital funding and accreditation conditional on fulfilling this simple program. Huge gains might not be seen overnight, but the culture of authority would begin to change. An early specific benefit could be a concern for quality improvement.

High-power distance cultures inevitably throw up more resistance to group self-appraisal, ${ }^{2}$ but the benefits to the practice of medicine should be proportional to the resistance encountered. This approach has the added advantage that it is not predicated on a direct challenge to any specific person or dogma. Change that comes from below, and within, is much more likely "to stick" than change brought from the outside or imposed from above. Case conference learning structured around reflexive learning will not instantly fix the problems of a professional culture that has been hostile to free and open questioning, but it will begin to address the root causes in a way that curricular reform and pedagogical technique cannot.

Conferences can transform the medical culture of authority. Purposeful repetition of an action that embodies a particular character value develops both the skill and the corresponding mind-set. Regular intentional questioning by discussing one's own uncertainties and failings as a community must surely promote communal learning and also the virtues of vulnerability, honesty, and caring. Without these virtues, the profession cannot be at its best. C.S. Lewis' wellknown treatment of the virtues illustrates this phenomenon, "When you are behaving as if you loved someone, you will presently come to love him." Instead of the feelings producing the action, it is the action that generally produces the feelings associated with the action, and even the capacity to experience those feelings and motives. The more we practice admitting our weaknesses, the easier it gets to do so and the easier it is to learn from the process of looking at our weaknesses.

\section{References}

1. Frenk J, Chen L, Bhutta Z, Cohen J, Crisp N, Evans $\mathrm{T}$ et al. Health professionals for a new century: transforming education to strengthen health systems in an interdependent world. The Lancet. 2010 Dec 4; 376 (9756): 1923-58. http://dx.doi.org/10.1016/S0140$\underline{6736(10) 61854-5}$

2. Hofstede, G. Culture's Consequences: Comparing Values, Behaviors, Institutions and Organizations Across Nations. Thousand Oaks, CA: Sage Publications; 2001.

3. Steinhardt LC, Waters H, Rao KD, Naeem AJ, Hansen P, Peters D. The effect of wealth status on care seeking and health expenditures. In: Afghanistan, 
Health Policy \& Planning. 2009; 24:1-17. http://dx.doi.org/10.1093/heapol/czn043

4. [i]dependent lens. [internet] Motherland Afganistan. [posted 17 Jan 2007; cited 12 June 2014]

http://www.pbs.org/independentlens/motherlandafghani $\underline{\text { stan/qa.html }}$
5. Easterly, W. The White Man's Burden: Why the West's Efforts to Aid the Rest Have Done So Much Ill and So Little Good. Oxford: Oxford University Press; 2009.

6. Lewis, C.S. Mere Christianity. New York:

Touchstone (Simon \& Schuster); 1996. [p.116].

This article was peer reviewed

Competing Interests: None declared.

Correspondence: Dr. Ken Foster 21 Maury's Run, Nobel, Ontario, Canada P0G 1 G0 kwinfer@gmail.com

Cite this article as: Foster, K.. Beyond "Teach a Man to Fish": Communal Meta-cognition as the Key to Sustainable Professional Development. Christian Journal for Global Health (August 2014), 1(1):60-63.

(C) Foster, K. This is an open-access article distributed under the terms of the Creative Commons Attribution License, which permits unrestricted use, distribution, and reproduction in any medium, provided the original author and source are properly cited. To view a copy of the license, visit http://creativecommons.org/licenses/by/4.0/

www.cjgh.org 